\title{
A INFLUÊNCIA DE UMA ABORDAGEM CONTEXTUAL SOBRE AS CONCEPÇÕES ACERCA DA NATUREZA DA CIÊNCIA DE ESTUDANTES DE FÍSICA
}

\author{
The influence of contextual approach \\ on the conceptions about the nature of science \\ among physics undergraduate students
}

\author{
Elder Sales Teixeira ${ }^{1}$ \\ Olival Freire Jr. ${ }^{2}$ \\ Charbel Niño El-Hani ${ }^{3}$
}

\begin{abstract}
Resumo: Este artigo apresenta os resultados de uma pesquisa qualitativa sobre as concepções de estudantes de física da Universidade Estadual de Feira de Santana (UEFS), Brasil, acerca da natureza da ciência e sua transformação por uma abordagem contextual do ensino de física. Esta abordagem foi desenvolvida em uma disciplina que aborda a mecânica clássica tendo em conta as dimensões históricas e filosóficas da atividade científica. Para a coleta de dados, utilizamos o questionário VNOS-C e entrevistas semiestruturadas. Os dados foram sistematizados por meio da construção de categorias baseadas nas respostas dos estudantes e, em seguida, foram submetidos a uma análise qualitativa. Os resultados apontaram para uma mudança significativa e favorável das concepções dos estudantes sobre a natureza da ciência em vários aspectos, a despeito da dificuldade observada de superação de algumas noções profundamente enraizadas em suas visões epistemológicas.
\end{abstract}

Palavras-chave: Abordagem contextual. Natureza da Ciência. Ensino de Física.

Abstract: This paper reports the results from qualitative research about Physics' students conceptions of the nature of science in a Brazilian public university, namely Universidade Estadual de Feira de Santana (UEFS). We also address how these conceptions have been changed by a contextual approach to physics teaching. This approach was developed in a course that deals with Classical Mechanics, taking into account the historical and philosophical dimensions of scientific work. Data were gathered by means of the questionnaire VNOS-C and semi-structured interviews. To systematize the data, categories were constructed based on the students' answers and, subsequently, were qualitatively analyzed. The results showed a significant and positive change in the students' conceptions about the nature of science in several respects, despite the difficulty of overcoming notions deeply rooted in their epistemological views.

Keywords: Contextual approach. Nature of science. Physics teaching.

${ }^{1}$ Licenciado em Física, Doutorando em Ensino, Filosofia e História das Ciências; Docente, Departamento de Física, Universidade Estadual de Feira de Santana (UEFS), BA, Brasil. eldersate@gmail.com

${ }^{2}$ Licenciado e Bacharel em Física, Doutor em História; Docente, Instituto de Física, Universidade Federal da Bahia (UFBA). Salvador, Ba, Brasil. freirejr@ufba.br

${ }^{3}$ Bacharel em Ciências Biológicas, Pós-Doutor em Estudos da Ciência e Filosofia da Natureza; Docente, Departamento de Biologia Geral, Instituto de Biologia, UFBA, Salvador, Ba, Brasil.

charbel.elhani@pesquisador.cnpq.br

${ }^{1}$ Universidade Estadual de Feira de Santana

Av. Transnordestina, s/n

Novo Horizonte - Feira de Santana, BA

44.036-900

529

Ciência \&̊ Educação, v. 15, n. 3, p. 529-556, 2009 
Teixeira, E. S.; Freire Jr., O.; El-Hani, C. N.

\section{Introdução}

O presente artigo relata os resultados de uma investigação qualitativa sobre o uso de uma abordagem contextual na prática pedagógica de um professor-investigador de física, no Ensino Superior. São investigadas as concepções acerca da natureza da ciência de estudantes de física da Universidade Estadual de Feira de Santana (UEFS), universidade pública do Nordeste brasileiro, localizada na cidade de Feira de Santana, estado da Bahia. Em particular, são analisadas as mudanças sofridas pelas concepções de alunos de física sobre determinados aspectos da natureza da ciência ao longo de uma disciplina baseada numa abordagem contextual do ensino de ciências, denominada 'Fundamentos de Física I', do Curso de Física dessa universidade. A metodologia da pesquisa envolve a aplicação do questionário VNOS-C (Views of Nature of Science, Form C), elaborado e validado por Norman Lederman e colaboradores, em pré- e pós-teste, bem como o uso de entrevistas semiestruturadas. Os dados são sistematizados por meio da construção de categorias baseadas nas respostas dos estudantes e, em seguida, submetidos a uma análise qualitativa.

Resultados preliminares da análise dos dados coletados nesse estudo foram apresentados em Teixeira, El-Hani e Freire (2001). O presente trabalho apresenta os resultados finais dessa análise, com um maior refinamento das categorias (conforme apresentado em TEIXEIRA, 2003) e a inclusão de uma análise individual, que constitui uma novidade em relação à própria dissertação de mestrado da qual esse trabalho foi derivado.

Nas seções seguintes serão feitas: uma revisão do debate acerca das visões sobre a natureza da ciência; uma síntese da experiência didática com o uso de uma abordagem contextual, que foi objeto de investigação neste trabalho; uma descrição da metodologia empregada; a apresentação dos resultados obtidos, e as discussões e conclusões derivadas.

\section{Revisando o debate sobre as visões sobre a natureza da Ciência}

Desde o início do século XX, pesquisadores em educação científica têm manifestado preocupação com as concepções de estudantes sobre a natureza da ciência e a necessidade de se incluir a instrução a este respeito no ensino de ciências, de modo a promover concepções mais adequadas acerca da empreitada científica (LEDERMAN, 1992). Mesmo antes, ainda no século XIX, esta preocupação já podia ser encontrada, por exemplo, em escritos de Ernst Mach (MATTHEWS, 1994). Contudo, no que concerne à instrução sobre a natureza da ciência, a ênfase recaiu, na maior parte do século passado, sobre a compreensão do que se entendia como o método científico. Mais recentemente, a visão a este respeito foi modificada, destacando-se a necessidade de se enfocar a história e filosofia das ciências propriamente ditas, e não somente o ensino sobre o "método científico" (LEDERMAN, WADE e BELL, 1998). A partir da década de 1960, a importância da história e filosofia das ciências para uma educação científica de qualidade foi frequentemente defendida na literatura, levando ao que tem sido denominado de uma abordagem contextual do ensino de ciências (e.g., ROBINSON, 1965; LEWIS, 1976; DUSCHL, 1985; HODSON, 1991; BURBULES e LINN, 1991; LEDERMAN, 1992; MATTHEWS, 1992, 1994, 2000; DRIVER et al., 1996; CARVALHO e VANNUCCHI, 1996, 2000; MONK e OSBORNE, 1997; MCCOMAS, ALMAZROA e CLOUGH, 1998; MCCOMAS, 1998; WANG e SCHMIDT, 2001; SEROGLOU e KOUMARAS, 2001; BELL 
A influência de uma abordagem contextual ...

et al., 2001; FREIRE JR. e TENÓRIO, 2001; FREIRE JR., 2002; EL-HANI, TAVARES e ROCHA, 2004; GATTI, 2005).

A crise contemporânea do ensino de ciências, evidenciada pelos altos índices de 'analfabetismo científico' e evasão de professores e alunos das salas de aulas de ciências, contribuiu para que a atenção dada à abordagem contextual do ensino de ciências aumentasse significativamente (MATTHEWS, 1992, 1994). Sintomaticamente, uma série de documentos de reforma educacional tem dado destaque, nas últimas décadas, à compreensão da natureza da ciência como um componente central da alfabetização científica (NCC, 1988; AAAS, 1993; RUTHERFORD e AHLGREN, 1995; NRC, 1996. Para uma revisão, ver MATTHEWS, 1994). É importante ter na devida conta, entretanto, que a introdução da história e filosofia das ciências na educação científica é condição necessária, mas não suficiente para promover uma adequada aprendizagem das ideias científicas (RUTHERFORD, 2001).

Lederman (1992), em um levantamento das pesquisas empíricas sobre a natureza da ciência como parte integrante dos objetivos da educação científica, identificou quatro linhas distintas de investigação: estudos acerca das concepções de estudantes sobre a natureza da ciência; desenvolvimento, implementação e teste de propostas destinadas à melhoria das concepções de estudantes sobre a natureza da ciência; pesquisas sobre as concepções de professores de ciências sobre a natureza do trabalho científico; investigações sobre as relações entre concepções de professores, práticas pedagógicas e concepções de estudantes.

As pesquisas acerca das concepções de estudantes sobre a natureza da ciência, a despeito da variação na metodologia (LEDERMAN, WADE e BELL, 1998), chegaram, geralmente, a resultados semelhantes, mostrando que os estudantes em geral apresentam concepções inadequadas sobre a natureza da ciência (AIKENHEAD, 1973; LEDERMAN e O'MALLEY, 1990; LEDERMAN, 1992; RYAN e AIKENHEAD, 1992; POMEROY, 1993; ROTH e ROYCHONDHURY, 1994; SOLOMON, DUVEEN e SCOT'T, 1994; ABRAMS e WANDERSEE, 1995; ROTH e LUCAS, 1997; HARRES, 1999; ABD-EL-KHALICK e LEDERMAN, 2000a, 2000b; MOSS, ABRAMS e ROBB, 2001). Entre as concepções inadequadas frequentemente encontradas entre os estudantes, podemos citar: ausência de compreensão sobre a natureza do conhecimento científico; compromisso com uma visão epistemológica absolutista, de acordo com a qual uma forma de conhecimento pode ser entendida como definitiva e absolutamente verdadeira; uma visão empírico-indutivista da ciência, segundo a qual o conhecimento científico é obtido por generalização indutiva a partir de dados de observação destituídos de qualquer influência teórica e/ou subjetiva, o que asseguraria a natureza verdadeira das proposições científicas; crença na existência de um método único, que seria capaz de assegurar a verdade absoluta das afirmações científicas sobre o mundo; ausência de reconhecimento do papel da criatividade e da imaginação na produção do conhecimento científico; falta de compreensão dos conceitos metateóricos 'fato', 'evidência', 'observação', 'experimentação', 'modelos', 'leis' e 'teorias', bem como de suas inter-relações etc. Uma das causas subjacentes a estes achados reside, de acordo com Lederman (1992), na carência de materiais instrucionais apropriados para a promoção de concepções epistemológicas mais adequadas entre os estudantes.

A partir desta constatação, duas linhas de investigação ganharam proeminência: uma voltada para avaliar a eficácia dos currículos direcionados para a construção de concepções adequadas sobre a natureza da ciência pelos estudantes; outra voltada para a investigação da compreensão dos professores sobre a natureza da ciência (LEDERMAN, 1992). 
Matthews (1994) faz uma apresentação bem fundamentada acerca da necessidade de melhorar a compreensão dos estudantes sobre a natureza da ciência, defendendo a incorporação da história e da filosofia das ciências na educação científica como um meio apropriado para atingir este objetivo. Contudo, ele próprio destaca, em artigo posterior, que quando assumimos como objetivo aprimorar as concepções de ciência de estudantes (bem como de professores) devemos ter em vista objetivos modestos. Ou seja, não devemos perder de vista que a proposta é fornecer a estudantes e professores instrumentos que lhes permitam compreender como o conhecimento é construído, suas possibilidades e limitações, suas relações com questões colocadas em domínios relacionados da atividade humana, como a produção e uso da tecnologia. Obviamente, não se pode esperar que os estudantes, ou futuros professores das ciências, se tornem competentes especialistas em história, sociologia e filosofia da ciência. As metas do ensino sobre a natureza da ciência são necessariamente mais modestas (MATTHEWS, 1998). Trata-se, na verdade, de uma posição que já se insinuava em seu livro Science Teaching, como podemos depreender da seguinte passagem: "Professores de ciências precisam conhecer algo da história e da natureza das disciplinas que eles estão ensinando" (MATTHEWS, 1994, p. 3, grifo nosso).

Uma diversidade de propostas metodológicas para a instrução sobre a natureza da ciência foi desenvolvida e testada em diferentes contextos (para revisões, ver LEDERMAN 1992; ABD-EL-KHALICK e LEDERMAN, 2000a). Estas propostas podem ser caracterizadas como 'implícitas', quando utilizam instrução sobre habilidades relacionadas à prática científica ou engajamento em atividades investigativas como um meio para a melhoria das visões sobre a natureza da ciência, ou 'explícitas', quando o ensino enfoca diretamente conteúdos epistemológicos ou emprega elementos de história e filosofia das ciências no tratamento de conteúdos específicos (ABD-EL-KHALICK e LEDERMAN, 2000a). Abordagens explícitas têm sido relativamente mais bem-sucedidas do que abordagens implícitas na promoção de melhorias das visões de professores em formação inicial ou em serviço sobre a natureza da ciência (LEDERMAN, 1999; AKERSON, ABD-EL-KHALICK e LEDERMAN, 2000; ABDEL-KHALICK e LEDERMAN, 2000a, 2000b; MOSS, ABRAMS e ROBB, 2001). Em vista disso, é recomendável que tentativas de promover mudanças das concepções epistemológicas de professores e estudantes tenham um caráter explícito e reflexivo ${ }^{4}$ (ABD-EL-KHALICK e LEDERMAN, 2000a). Moss, Abrams e Robb (2001) defendem, contudo, a confluência dos dois tipos de abordagem, apesar de reconhecerem a maior eficácia da abordagem explícita. Eles têm em vista a ideia de que, uma vez ativamente engajado no fazer científico, o estudante pode ser conduzido a uma compreensão mais plena da natureza de tais atividades. Esta compreensão requer, contudo, a explicitação das discussões sobre a natureza da ciência no decorrer das atividades investigativas, sob pena de poder reforçar, inclusive, visões epistemologicamente inadequadas, como o indutivismo ingênuo.

Estudos empíricos sobre a eficácia do uso de abordagens contextuais no ensino de ciências, e, em particular, da física têm sido realizados (SOLOMON et al., 1992; AKERSON,

\footnotetext{
${ }^{4}$ Neste contexto, quando se referem à 'reflexividade', Abd-El-khalick e Lederman (2000a) têm em vista práticas de formação que deem aos indivíduos a oportunidade de uma reflexão acerca de suas próprias experiências, a partir de uma abordagem explícita de alguns aspectos da natureza da ciência.
} 
ABD-EL-KHALICK e LEDERMAN, 2000). Um deles, feito por Cudmani e Sandoval (2000), em disciplinas de conteúdos específicos de cursos de graduação em física (Licenciatura e Bacharelado) e engenharia, informadas pelas dimensões históricas e filosóficas da atividade cientifica, mostrou que, a despeito de alguns focos de resistência, a abordagem contextual promoveu mudanças significativas na compreensão dos estudantes acerca da natureza da ciência.

Nas pesquisas iniciais sobre currículos e/ou materiais instrucionais voltados para o ensino de história e filosofia das ciências, assumia-se que apenas tais currículos e/ou materiais poderiam ser suficientes para propiciar uma melhor compreensão sobre a natureza da ciência, perdendo-se de vista a importância do professor como variável interveniente. A implicação desta assunção era que um professor poderia promover o desenvolvimento de um entendimento adequado sobre a natureza da ciência em seus alunos mesmo que ele próprio não possuísse uma concepção adequada. Bastaria submeter os alunos aos currículos e/ou materiais instrucionais para que o objetivo pudesse ser alcançado (LEDERMAN, 1992). Esta suposição foi criticada ainda em 1965 por Trent (1965), que reconheceu que, sendo um determinado currículo eficaz para um professor, mas não para outro, e tendo sido controlada a variável habilidade do aluno, então o conhecimento do professor sobre a natureza da ciência deveria aparecer como um fator significativo de interferência. Esta compreensão conduziu os pesquisadores a enxergarem, na visão sobre a natureza da ciência do professor, um outro foco de pesquisa a ser desenvolvido (LEDERMAN, 1992).

Independentemente dos instrumentos de pesquisa utilizados, os estudos realizados constataram que os professores, assim como os estudantes, em geral possuem concepções epistemológicas inadequadas. Entre os professores, também predominam visões empíricoindutivistas e absolutistas da natureza da ciência, a despeito da variação de fatores, como: o contexto cultural, a experiência de ensino e o nível de atuação e de formação (BRICKHOUSE, 1989, 1990; NUSSBAUM, 1989; CLEMINSON, 1990; KING, 1991; GALLAGHER, 1991; LEDERMAN, 1992; POMEROY, 1993; ABELL e SMITH, 1994; LAKIN e WELLINGTON, 1994; ABD-EL-KHALICK e BOUJAOUDE, 1997; HARRES, 1999; AKERSON, ABDEL-KHALICK e LEDERMAN, 2000; GIL-PÉREZ et al., 2001). Em poucos casos, a depender do instrumento de coleta de dados, apareciam visões mais contextualizadas e menos absolutistas (HARRES, 1999). Esses achados estimularam a elaboração e o teste de propostas destinadas à melhoria das visões dos professores sobre a natureza da ciência.

Muitas intervenções visando o aprimoramento das concepções epistemológicas de professores pressupunham que essas concepções seriam transferidas de modo direto para suas práticas pedagógicas (LEDERMAN, 1992; ABD-EL-KHALICK e LEDERMAN, 2000b). Esse pressuposto foi colocado em questão com o surgimento de um novo foco de pesquisa nas investigações sobre a natureza da ciência no contexto do ensino e da aprendizagem. Os estudos sobre as relações entre concepções de professores, práticas pedagógicas e concepções de estudantes mostraram que a suposição de uma influência direta das concepções epistemológicas dos professores sobre sua prática em sala de aula e, em seguida, sobre as concepções dos estudantes era muito simplista. Esta influência é modulada por um conjunto de variáveis envolvidas no processo de ensino e aprendizagem, próprias da natureza complexa da sala de aula. Não causa espanto, então, que algumas investigações não tenham conseguido estabelecer uma correspondência entre as concepções dos professores e sua conduta em sala de aula (LEDERMAN e ZEIDLER, 1987; MELLADO, 1997), enquanto outras tenham encontrado uma correlação entre a concepção acerca da natureza da ciência e a prática pedagógica do 
Teixeira, E. S.; Freire Jr., O.; El-Hani, C. N.

professor (BRICKHOUSE, 1990; PORLÁN, 1994; PORLÁN, RIVERO e MARTIN DEL POZO, 1997; SEPULVEDA, 2001). Esses resultados discrepantes decorrem precisamente da interferência de fatores intervenientes que podem facilitar ou impedir relações efetivas entre concepções dos professores, suas práticas pedagógicas e concepções dos estudantes (LEDERMAN, 1999). Tais fatores consistem em variáveis contextuais associadas à atividade pedagógica, como, por exemplo: restrições institucionais e curriculares, a falta de recursos para avaliar a compreensão sobre a natureza da ciência, a experiência e as intenções dos professores, e o conhecimento prévio, as percepções, a motivação e as habilidades dos alunos, entre outros (BRICKHOUSE e BODNER, 1992; ABD-EL-KHALICK, BELL e LEDERMAN, 1998; LEDERMAN, 1999; ABD-EL-KHALICK e LEDERMAN, 2000a; MASSONI, 2005).

Pode-se concluir, então, que a posse de concepções adequadas sobre a natureza da ciência pelo professor é uma condição necessária, mas não suficiente, para a melhoria das concepções epistemológicas dos estudantes (ABD-EL-KHALICK e LEDERMAN, 2000b; LEDERMAN, 1992). Isso não diminui, contudo, a importância de intervir-se sobre aquelas concepções. Obviamente, um docente não poderá ensinar aos estudantes concepções adequadas sobre a natureza da ciência se ele próprio possuir uma concepção inadequada. Além disso, deve-se considerar que, mesmo em situações nas quais não é clara a relação entre as concepções epistemológicas de professores e sua prática pedagógica, é bastante provável que os estudantes estejam aprendendo sobre a natureza da ciência, de modo tácito e acrítico, por meio do currículo oculto (HODSON, 1991).

Neste trabalho, tomamos a decisão de avaliar a adequação das visões dos estudantes sobre a natureza da ciência antes e após a intervenção pedagógica. É compreensível que esta decisão se mostre, para muitos, controversa. As propostas de uso de abordagens contextuais do ensino de ciências como meio para aprimorar as concepções epistemológicas de professores e estudantes se deparam com controvérsias no que diz respeito ao que constituiria um grau satisfatório de compreensão sobre a natureza da ciência. Pode-se questionar se é realmente possível falar em uma concepção adequada de ciência e, até mesmo, se vale a pena incluir a filosofia das ciências em programas de formação de professores (ver MARTIN, KASS e BROUWER, 1990; ALTERS, 1997). Afinal, os próprios filósofos da ciência, educadores e cientistas não partilham de um consenso sobre o que vem a ser um entendimento epistemológico apropriado da atividade científica (MCCOMAS, ALMAZROA e CLOUGH, 1998; ABD-EL-KHALICK e LEDERMAN, 2000a; GIL-PÉREZ et al., 2001). Parece difícil, dessa forma, estabelecer a existência de alguma visão consensual acerca da natureza da ciência em um nível mais profundo de compreensão (LEACH et al., 2000).

No entanto, a ênfase sobre as divergências tende a ocultar o fato de que há também um grau relativamente alto de concordância sobre alguns aspectos de uma visão adequada sobre a natureza da ciência (MCCOMAS, ALMAZROA e CLOUGH, 1998; ABD-EL-KHALICK e LEDERMAN, 2000b; GIL PÉREZ et al., 2001). Além disso, não podemos perder de vista que muitos dos pontos sobre os quais filósofos, cientistas e educadores discordam, no que tange à natureza da ciência, são mais complexos e fogem ao âmbito da compreensão dos estudantes (cf. ABD-EL-KHALICK e BOUJAOUDE, 1997; MOSS, ABRAMS e ROBB, 2001), não sendo preciso nem desejável que estejam presentes numa abordagem pedagogicamente adequada das dimensões históricas e filosóficas das ciências. Não se pode, é claro, afirmar que exista alguma visão única sobre a natureza da ciência ou, mesmo, um consenso a respeito de alguma imagem 'correta' da atividade científica. Não há como negar a natureza multifacetada, complexa e dinâ- 
mica do trabalho científico, bem como das análises filosóficas da empreitada científica. Trata-se somente de assumir que, como argumentam Abd-El-khalick e Lederman (2000b), deve ser possível chegar a um termo comum sobre o que pode ser considerada uma visão adequada sobre a natureza da ciência, de acordo com as concepções epistemológicas predominantes num dado período. Assume-se aqui, portanto, que é possível propor um número de características atualmente pouco ou não controversas sobre a natureza da ciência em acordo com uma visão pós-positivista da ciência, visão esta que passa a tomar corpo a partir da década de sessenta (ver LAUDAN, 2003; MCEVOY, 2007; ROSA, 2006). Este parece ser o caso, em particular, se tivermos em conta os objetivos necessariamente modestos de cursos de história e filosofia das ciências para estudantes e professores (cf. MATTHEWS, 1998). Por exemplo, seria difícil, na atualidade, rejeitar a dependência teórica da observação ou concordar com a ideia de que haveria um método científico único. Assim, podemos tanto estabelecer quais objetivos devemos assumir ao ensinarmos professores e estudantes sobre a natureza da ciência, como avaliarmos o grau de adequação e a evolução de suas concepções epistemológicas.

Em um trabalho anterior, que também empregou o VNOS-C, utilizamos sumários de ideias largamente aceitas sobre a natureza da ciência apresentados por Mccomas, Almazroa e Clough (1998) e Gil-Pérez et al. (2001) como base para a construção de critérios para a avaliação das concepções epistemológicas dos estudantes. Foram também utilizados, como marcos de referência, comentários incluídos pelos autores do questionário VNOS-C em uma versão do instrumento dirigida para pesquisadores. Estes critérios nortearam a construção de marcos de referência para a avaliação do grau de adequação das respostas dadas pelos alunos a cada questão do questionário VNOS-C (ver EL-HANI, TAVARES e ROCHA, 2004). No presente artigo, além dos referenciais mencionados acima, foram também utilizadas, para a construção de critérios que permitissem avaliar o grau de adequação e a evolução das visões dos estudantes sobre a natureza da ciência, características da atividade científica identificadas por Abd-Elkhalick e Lederman (2000b), e Akerson, Abd-El-khalick e Lederman (2000). Segundo tais características, o conhecimento científico pode ser considerado como de natureza tentativa; empiricamente embasado; subjetivo ${ }^{5}$; parcialmente embasado em inferências, imaginação e

\footnotetext{
${ }^{5}$ Diferentemente de Abd-El-khalick e Lederman (2000b) e Akerson, Abd-El-khalick e Lederman (2000), não consideramos que o conhecimento científico seja subjetivo. Em nossa visão, há uma diferença importante entre reconhecer o envolvimento dos sujeitos e, logo, de fatores subjetivos na construção do conhecimento, e afirmar que o conhecimento, em si mesmo, é subjetivo. Ao traçarmos essa distinção, apoiamo-nos numa concepção da 'objetividade' que remete à visão wittgensteiniana de que a objetividade não está ligada a proposições, mas às práticas dos seres humanos (cf. WITTGENSTEIN, 1969). Desse modo, não nos comprometemos com visões mais tradicionais sobre a objetividade, de acordo com as quais esta se vincularia a crenças sobre o mundo que supostamente seriam independentes da mente que conhece. A visão wittgensteiniana da objetividade diz respeito à busca da imparcialidade nas ações, ou seja, a métodos ou procedimentos que buscam evitar vieses. Nesses termos, o conhecimento científico pode alcançar um grau elevado de objetividade, não por alguma relação especial, de natureza extralinguística e não-social, que poderia estabelecer com o mundo, mas devido ao seu caráter público e ao uso de uma série de procedimentos, pela comunidade científica, de controle racional mútuo, de crítica sistemática e continuada das teorias e hipóteses, dos métodos e da evidência, em suma, dos vários elementos que comparecem nos jogos de linguagem da ciência.
} 
criatividade humanas; social e culturalmente situado. Estes autores acrescentam ainda dois aspectos: as distinções entre observação e inferência, e entre as funções de teorias e leis. Essas características são enfatizadas também em documentos de reforma educacional, como aqueles produzidos pela American Association for the Advancement of Science (RUTHERFORD e AHLGREN, 1995) e pelo National Research Concil (NRC, 1996).

Apesar de termos sempre buscado trabalhar com critérios relacionados a ideias nas quais detectávamos um grau considerável de concordância na filosofia da ciência, isso não implica que nossas opções filosóficas, como pesquisadores e professores, não tenham desempenhado qualquer papel na análise dos dados. Seria impossível negar a interferência de nossas próprias concepções epistemológicas na análise dos questionários. Trata-se somente de que assumimos e procuramos manter uma atitude reflexiva e epistemologicamente vigilante diante de nossas próprias opções, evitando utilizá-las como parâmetros únicos, ou mesmo principais, para a avaliação da adequação das visões dos alunos.

Como vimos acima, a inclusão da história e filosofia das ciências nos currículos escolares tem sido um dos pontos de maior consenso na literatura a respeito da educação científica. Entretanto, este consenso não tem sido acompanhado por uma quantidade significativa de relatos de pesquisas empíricas sobre a inclusão das dimensões históricas e filosóficas no ensino de ciências. Isso mostra uma discrepância entre o que se propõe (em termos de ênfases curriculares) e o que se pratica (em termos de currículos postos em ação pelos educadores), particularmente no ensino de física (que constitui o foco deste artigo), o que parece refletir uma dificuldade de traduzir propostas baseadas no uso da história e filosofia das ciências em práticas na sala de aula (CARVALHO e VANNUCCHI, 1996).

\section{Uma experiência com uma abordagem contextual do ensino de Física}

Matthews (1994) reconheceu duas perspectivas para o uso de abordagens contextuais no ensino de ciências: de um lado, uma minimalista, que consiste na inclusão de alguns tópicos isolados sobre determinados fatos históricos e datas, pequenas biografias, alguns conceitos epistemológicos etc., quando determinados assuntos forem estudados (como ocorre em muitos livros didáticos. Ver, por exemplo, LEITE, 2002). De outro, uma maximalista, na qual as dimensões históricas, filosóficas e culturais da ciência permeiam um currículo como um todo, sendo abordadas explicitamente, ou o próprio currículo seja organizado em bases históricas. Trata-se de uma forma mais plena de se usar a abordagem contextual, que pode ser encontrada em programas como o Projeto de Física de Harvard ou os Estudos de Casos de Harvard em Ciência Experimental (MATTHEWS, 1994). Uma posição intermediária é uma na qual algumas porções do processo de ensino e aprendizagem são organizados em bases históricas (LEITE, 2002). Estas duas últimas posições contribuem para a superação de problemas importantes encontrados nas abordagens minimalistas, como: a quase-história, o presentismo ou anacronismo, o whiggismo, a redução da história das ciências à biografia de cientistas, ou o desequilíbrio entre história interna e externa (BRUSH, 2000; LEITE, 2002); ou, ainda, a virtual ausência da dimensão filosófica e a insuficiente consideração da dimensão sociológica e cultural das ciências nos currículos escolares (HANSEN, 2002; ZIMAN, 2002). Por esta razão, na construção da proposta instrucional que desenvolvemos e testamos, foi feita uma opção cons- 
ciente por uma abordagem mais próxima do extremo maximalista descrito por Matthews. Esta proposta será descrita a seguir.

A proposta foi desenvolvida e testada em um curso de física de nível superior de uma universidade pública da região Nordeste do Brasil (Universidade Estadual de Feira de Santana, UEFS), que tem como objetivo a formação inicial tanto de professores quanto de bacharéis. No currículo do curso, constam três disciplinas denominadas 'Fundamentos de Física I, II e III', que têm como objetos de estudo, respectivamente, mecânica clássica, termodinâmica e eletromagnetismo. Essas disciplinas foram incluídas no currículo no final da década de 1990, com a expectativa de que os conceitos de física abordados fossem trabalhados de maneira contextual.

A disciplina 'Fundamentos de Física I' era cursada por alunos recém-ingressos na universidade, no primeiro semestre do curso ${ }^{6}$. A disciplina se ocupa da mecânica clássica, enfocando o estudo dos movimentos, de sua descrição, causa e conservação. O programa da disciplina se inicia com a concepção de movimento dos gregos antigos, com ênfase nas ideias de Aristóteles. Em seguida, são abordadas brevemente as concepções medievais, destacando-se a apropriação e interpretação da filosofia aristotélica, as contribuições dos estudiosos das escolas de Oxford e Paris para as tentativas de tratar matematicamente conceitos físicos, como o de velocidade, e para a construção da teoria do ímpeto, e o modelo heliocêntrico de Copérnico.

O tratamento do movimento introduzido por Galileo e os conflitos entre as visões de mundo aristotélico-tomista e galileana são discutidos a seguir, tratando-se de conceitos como os de movimentos uniforme e uniformemente variado, e inércia, bem como da lei de queda dos corpos. São também discutidos aspectos metodológicos, abordando-se o uso mais sistemático da matemática e da experimentação por Galileo, e as consequências da revolução científica do século XVII para a constituição da sociedade e da ciência modernas.

Chega-se, assim, à contribuição de Newton, considerando-se suas três leis do movimento e a lei da gravitação universal. O papel de teorias e leis, como formas do conhecimento científico, é discutido a esta altura, destacando-se as diferenças e relações entre elas. Em relação à primeira lei de Newton, o significado e a importância dos referenciais inerciais são tratados. Em relação à segunda lei, destaca-se seu caráter determinista e, em relação à terceira, discute-se o princípio de conservação do momento linear. Neste ponto, destaca-se a importância de Descartes como possível precursor deste princípio, bem como sua contribuição para a formulação das leis de Newton, por meio de sua ideia de 'leis da natureza'. É feita, ainda, uma discussão sobre os conceitos de espaço e tempo absolutos de Newton, apontando-se a importância de tais conceitos para a validade das suas leis de movimento, devido à dependência destas em relação aos referenciais inerciais. Em relação à lei da gravitação universal, a contribuição de Kepler é abordada.

\footnotetext{
${ }^{6}$ Após uma mudança curricular em 2005, esta disciplina passou a ser optativa.
} 
O programa da disciplina termina com as críticas de Mach à teoria newtoniana, quando se apresenta o 'Princípio de Mach' e são discutidos os conflitos entre o seu conceito de inércia e o de Newton, tomando-se, como exemplo, o experimento do balde girante. Neste ponto, a questão da natureza tentativa das teorias científicas é trazida à tona, a partir da discussão destas teorias científicas concorrentes.

No semestre em que foi realizada a intervenção relatada no presente trabalho, textos originais de Galileo, Newton e Descartes foram trabalhados em sala de aula, além de textos de historiadores das ciências, como Koyré, Thuillier, Drake, entre outros. Entre os recursos didáticos empregados, encontrava-se um aparato experimental, a saber, um pêndulo simples. Foi realizada, na sala de aula, a reprodução e discussão do experimento do pêndulo simples, minuciosamente descrito e supostamente realizado por Galileo. Neste ponto, foram discutidas as controvérsias entre historiadores como Koyré (1982) e Drake (1980) quanto à verossimilhança da realização de tais experimentos por Galileo, e problemas relativos aos contextos da descoberta e da justificação no trabalho desse naturalista, colocando-se em questão, neste caso, posições discordantes, como as de Mach (1949) e Settle (1967).

\section{Metodologia}

O presente trabalho foi orientado por um modelo de pesquisa eminentemente qualitativo, uma vez que o ambiente natural da sala de aula constituiu uma das fontes dos dados coletados, e um dos pesquisadores, na condição de professor-investigador, foi o principal responsável por tal coleta; os dados coletados foram de natureza sobretudo descritiva, com as afirmações feitas sendo subsidiadas por citações frequentes das respostas dadas pelos alunos às questões da ferramenta utilizada; a pesquisa foi marcada por uma preocupação constante com o processo de ensino e aprendizagem no ambiente da sala de aula; os significados das respostas dos alunos ao instrumento estiveram no foco da investigação todo o tempo; e a análise dos dados teve como objetivo uma descrição das categorias de respostas fornecidas pelos alunos e de seus padrões de mudanças ao longo de uma abordagem contextual do ensino de física, e não o teste de hipóteses definidas anteriormente (LÜDKE e ANDRÉ, 1986)

A pesquisa foi realizada com estudantes do Curso de Física da UEFS, que cursavam a disciplina 'Fundamentos de Física I', descrita na seção anterior. A pesquisa foi realizada entre outubro de 2000 e abril de 2001. Nesse período, havia 124 estudantes matriculados na disciplina. A turma investigada continha, contudo, 56 alunos inicialmente, sendo 4quarenta recémingressos e 16 repetentes de semestres anteriores. Entre os estudantes, 31 participaram da pesquisa na primeira (pré-teste) e segunda etapas (pós-teste).

\section{Instrumentos de coleta de dados}

Dois instrumentos de coleta de dados foram empregados na investigação aqui relatada: inicialmente, um questionário aberto foi aplicado a uma amostra de alunos, a partir da qual foi selecionada uma subamostra para a realização de entrevistas semiestruturadas.

Utilizamos o questionário VNOS-C (Views of Nature of Science - Form C; Visões da Natureza da Ciência - Modelo C), elaborado e inicialmente validado por Lederman et al. 
(2001, 2002), na forma de pré- e pós-testes. Este questionário contém 10 questões abertas que se destinam a avaliar uma série de aspectos relacionados às concepções dos estudantes sobre a natureza da ciência, como os seguintes: o que vem a ser a ciência; sua relação com experimentos; a relação entre modelo e realidade; noções sobre teorias e leis; o papel da criatividade e imaginação na produção científica; a natureza tentativa do conhecimento científico; a influência de fatores socioculturais sobre a prática científica etc. A versão traduzida do questionário foi inicialmente validada por retrotradução e, posteriormente, testada em estudo piloto com 23 alunos de uma disciplina do Curso de Ciências Biológicas da UFBA, ministrada por um dos autores. O questionário VNOS-C, na versão traduzida para o português que foi empregada neste estudo, é apresentado no Anexo 1.

A principal característica que levou à opção pelo questionário VNOS-C foi a possibilidade de coletar dados concernentes às visões acerca da natureza da ciência, de uma grande quantidade de estudantes, com uma ferramenta relativamente simples. Além disso, trata-se de questionário elaborado e validado por uma equipe de pesquisa que tem significativa experiência em investigações sobre o tema. Uma possível desvantagem desta ferramenta reside no fato de ser baseada em questões abertas, o que torna mais difícil a comparação com resultados obtidos em outras pesquisas. No entanto, esta característica também traz uma vantagem, na medida em que propicia, sobretudo com o complemento das entrevistas, uma análise mais fidedigna do significado das ideias dos estudantes sobre os aspectos abordados no questionário.

A análise dos dados obtidos com o questionário foi auxiliada pelos resultados obtidos por meio das entrevistas semiestruturadas, que foram realizadas e gravadas poucos dias após a aplicação do questionário na primeira etapa, como forma de refinar a interpretação das respostas dadas aos alunos às questões que o compunham. As entrevistas foram realizadas com uma subamostra de dez estudantes, o que corresponde a 25\% dos participantes da primeira etapa de coleta de dados. Como o pós-teste foi realizado no final do semestre letivo, não houve possibilidade de se realizarem entrevistas naquela ocasião, em função do envolvimento dos estudantes com avaliações.

Nas entrevistas, os estudantes tiveram a oportunidade de elaborar oralmente suas ideias a respeito das mesmas questões presentes no questionário, podendo, assim, reafirmar, aprimorar ou contradizer as visões que haviam anteriormente exposto por escrito. Antes de ser entrevistados, os estudantes tiveram acesso às suas próprias respostas ao questionário, para uma breve leitura.

\section{Tratamento dos dados}

Inicialmente, foi feita uma análise geral, a partir da qual foram estabelecidas algumas categorias para a classificação das respostas a cada questão. As categorias foram construídas mediante a reunião de respostas que continham teor similar, ou seja, a mesma ideia central sobre o tema abordado em cada item do questionário. As categorias obtidas devem ser entendidas, pois, como sínteses das ideias centrais compartilhadas por um determinado conjunto de respostas. Vale ressaltar que tais categorias não foram preestabelecidas, mas ao contrário, sua elaboração foi resultado da própria análise dos dados, envolvendo uma discussão constante entre os pesquisadores, de modo a refiná-las gradualmente. Além disso, na construção das categorias, os dados oriundos das entrevistas se mostraram bastante importantes, na medida 
em que permitiram uma compreensão mais aprofundada das ideias apresentadas nas respostas de diferentes estudantes às questões do VNOS-C.

$\mathrm{Na}$ análise de algumas questões, foi necessário incluir uma categoria de 'respostas não compreendidas', contendo respostas muito vagas, demasiadamente genéricas ou pouco consistentes, das quais não se pôde extrair um significado preciso do que os estudantes pretendiam afirmar.

Foi feita uma quantificação da frequência de respostas em cada categoria. Isso serviu de base para uma análise qualitativa geral, que envolveu as seguintes etapas: (1) uma apreciação do significado de cada categoria em termos de sua adequação relativamente a ideias largamente aceitas sobre a natureza da ciência (ver Introdução); (2) uma apreciação geral das transformações sofridas pelas respostas dos estudantes acerca dos aspectos epistemológicos tratados no questionário, após terem cursado uma disciplina de física informada por uma abordagem contextual; (3) uma apreciação da relação destas transformações com a própria disciplina, na qual se buscou analisar se e como transformações observadas nas respostas de cada aluno poderiam ser relacionadas a aspectos específicos do trabalho realizado em sala de aula. Os resultados oriundos desta parte da análise geral estão publicados em Teixeira, El-Hani e Freire (2001), bem como em Teixeira (2003) de maneira mais refinada.

Em seguida, foi feita uma análise das mudanças sofridas pelas respostas de cada estudante, buscando-se traçar um perfil individual do desempenho dos mesmos no que diz respeito às transformações observadas em suas respostas sobre aspectos determinados na natureza da ciência. Para tanto, as respostas foram classificadas como 'satisfatórias' (S), 'parcialmente satisfatórias' (PS) e 'insatisfatórias' (I). Esta classificação serviu como marco de orientação para uma nova análise das respostas de cada estudante a cada questão do VNOS-C e também para uma comparação entre os percentuais de respostas classificadas como S, PS e I nas duas etapas (ver Tabela 2). Com isso, pôde-se fazer uma avaliação qualitativa mais aprofundada da evolução das concepções de cada estudante sobre a natureza da ciência, individualmente.

Como forma de conferir maior consistência à interpretação dos dados brutos (as respostas dos alunos), dois pesquisadores que não estiveram diretamente envolvidos em sua produção e análise inicial discutiram as interpretações das respostas e as categorias construídas, comparando-as sistematicamente com os dados brutos. As diferenças de interpretação detectadas foram discutidas por todos os pesquisadores envolvidos, buscando-se o maior nível de consenso possível sobre a interpretação das respostas e suas relações com as categorias nas quais haviam sido classificadas.

Cabe ressaltar, ainda, que, por motivo de cautela, excluímos do presente trabalho o tratamento e a análise dos dados referentes à questão sete do VNOS-C, em vista da dificuldade sentida pelos estudantes de física investigados de lidar com o conceito de biologia mobilizado pela pergunta. Pareceu-nos que as respostas fornecidas não ofereciam indicações seguras sobre as ideias dos estudantes acerca das relações entre evidências e o grau de confiança que pode ser atribuído a conceitos científicos. 


\section{Resultados e análises}

\section{Análise geral}

Em relação aos resultados obtidos com a análise geral, será apresentada aqui apenas uma síntese dos mesmos, uma vez que já se encontram publicados em Teixeira, El-Hani e Freire (2001), bem como em Teixeira (2003). A Tabela 1 ilustra uma síntese do teor das categorias encontradas. Foi percebido que houve uma maior abrangência nas concepções de ciência dos estudantes. Houve uma redução significativa da visão empirista ingênua, embora esta ainda permanecesse predominante em relação às demais visões, conforme se pode ver nas tabelas. Por outro lado, houve o surgimento e o acréscimo de outras visões que representavam ideias mais maduras. A despeito da concepção empirista ingênua permanecer predominante, a sua brusca redução, juntamente com o substancial aumento de visões mais adequadas, levou a um entendimento de que parece ter havido um amadurecimento na compreensão dos estudantes quanto ao papel que o experimento exerce na produção científica. Percebeu-se também uma redução substancial da visão realista ingênua, que aceita os modelos como retratos fiéis da realidade, ao tempo em que houve um acréscimo da visão que reconhece as limitações dos modelos científicos. Portanto, parece ter havido um amadurecimento na percepção da natureza tentativa do conhecimento científico. Quanto às concepções sobre os conceitos de teorias e leis científicas, não apareceu qualquer visão adequada na etapa inicial. Já na etapa final, as visões consideradas inadequadas diminuíram e a visão que predominou foi a que compreendia teorias como tentativas de explicação de fenômenos e leis como relações entre fenômenos e/ ou grandezas, portanto, uma visão adequada. Esta mudança favorável pode ser atribuída à discussão explícita que foi realizada durante a disciplina sobre tais conceitos.

Sobre a questão das mudanças nas teorias científicas, a concepção predominante no início era mais limitada, reconhecendo tais mudanças em função do acúmulo de novas observações e do uso de novas tecnologias. Ao final, houve uma redução desta visão com o aumento de visões mais interessantes reconhecendo as limitações das teorias ou a re-interpretação das mesmas como razões para tais mudanças. O reconhecimento da interferência de aspectos subjetivos na ciência não pareceu ser um ponto de dificuldade na compreensão dos estudantes; e sobre a influência de valores socioculturais na ciência foi percebido que a visão mais ingênua de uma ciência "livre de valores sócio-culturais" se reduziu consideravelmente, ao passo que visões mais maduras, de uma ciência que sofre o impacto de tais valores, aumentaram levando, portanto, à conclusão de que parece ter havido um ganho na compreensão dos estudantes. 
Teixeira, E. S.; Freire Jr., O.; El-Hani, C. N.

Tabela 1. Síntese do teor das categorias encontradas em cada item do questionário após a análise geral.

QUESTÕES CATEGORIAS (SÍNTESE)

1. O que é ciência?
(a) Estudo dos fenômenos da natureza.
(b) Conjunto de conhecimentos organizados.
(c) Desenvolvimento de métodos.
(d) Comprovação dos fatos.

2. O que torna a ciência diferente de outras formas de investigação?

3. O que é um experimento? (a) Objeto de estudo.

(b) Método (validação experimental).

(c) Seu caráter internalista.

(d) Religião e filosofia fazem parte da ciência.

(e) Ciência sempre muda, religião não.

(a) Procedimento para provar e validar teorias.

(b) Teste de teorias através de tentativa e erro.

(c) Uma das etapas da construção e aplicação de idéias.

(d) Reprodução de um fenômeno em laboratório.

(e) Método de testar fenômenos.

(f) Método de testar hipóteses de forma controlada.

4. O desenvolvimento do conhecimento científico requer experimentos?

(a) Sim, por ser o critério de veracidade das teorias.

(b) Sim, para mostrar se uma teoria é verdadeira ou falsa.

(c) Não, pois há conhecimentos obtidos sem necessidade de comprovação experimental.

(d) Sim, para que se possa reproduzir fenômenos com controle de variáveis.

(e) Sim, para solucionar problemas no desenvolvimento de uma teoria.

5. Qual o grau de certeza que os cientistas têm acerca da estrutura do átomo?

(a) Alto, pois os experimentos sofisticados levam a modelos que reproduzem bem a realidade.

(b) Alto, porque usaram o modelo do sistema solar como evidência para a forma do átomo.

(c) Indefinido, o modelo atual é aceito por parecer o melhor.

(d) Baixo, porque os experimentos não davam confirmação.

(e) Baixo, por se tratar apenas de um modelo teórico na tentativa de representar o átomo.

6. Você acha que há diferença entre uma teoria científica e uma lei científica?

(a) Teorias não têm comprovação, leis são comprovadas experimentalmente.

(b) Teorias evoluem tornando-se leis quando há mais evidências e comprovação experimental.

(c) Teorias sofrem mudanças e leis são imutáveis.

(d) Não há diferença, têm o mesmo significado.

(e) Leis são comprovadas facilmente, teorias também são comprovadas, mas não tão facilmente.

(f) Teorias são explicações de fenômenos e leis expressam relações entre os fenômenos.

7. Você acha que uma teoria pode transformar-se? Se sim explique por que as teorias mudam. Por que nós nos preocupamos em aprender teorias científicas, se elas podem transformar-se?

8. Os cientistas usam sua criatividade e imaginação durante suas investigações?

(a) Sim, através de novas tecnologias e experimentos. Aprender para acompanhar a evolução das teorias.

(b) Sim, pois sob novos pressupostos podem surgir teorias melhores. Aprender para entender seus equívocos.

(c) Sim, por serem limitadas. Aprender para melhor compreender suas mudanças.

(a) Sim, em todos os estágios da investigação.

(b) Sim, em parte da sua atividade para propor novas idéias e problemas ou na coleta de dados.

(c) Sim, como instrumento para interpretar o que não é diretamente visível e na criação de modelos para representar a realidade. Mas, não deve ser usado como critério final definitivo.

(d) Não, porque seu trabalho é fundamentado na realidade trazida à tona pela experiência e não em hipóteses mentais. 
A influência de uma abordagem contextual ...

Tabela 1. continuação

QUESTÕES

9. Como dois grupos de cientistas que tiveram acesso aos mesmos dados poderiam chegar a conclusões diferentes?

10. A ciência reflete valores sociais e culturais ou é universal?

\section{CATEGORIAS (SÍNTESE)}

(a) Porque se utilizam da criatividade e imaginação e seus valores sociais e culturais, bem como ideologias, são distintos, o que os leva a respostas diferentes.

(b) Os dados não são evidentes e precisos o suficiente para que não haja dúvidas sobre as conclusões.

(c) A busca por uma resposta, a competição, leva os cientistas a 'empurrarem' uma saída.

(a) Culturas distintas possuem formas distintas de pensar, criar, produzir; assim, a produção científica também será diferente quando realizada por povos diferentes, refletindo valores culturais, sociais e econômicos.

(b) Teorias científicas são analisadas pela comunidade científica do mundo todo, que estabelece os critérios de validade. Uma teoria, quando aceita, o é em qualquer parte do mundo. Portanto, a ciência tem caráter universal.

(c) A ciência tem os dois aspectos: pesquisas são realizadas para atender a necessidades regionais, logo reflete e influencia valores locais; contudo, a ciência também produz conhecimentos úteis para a humanidade, independentemente de ideologias, culturas e políticas sendo, portanto, universal.

\section{Análise individual}

A Tabela 2 apresenta, de forma condensada, as informações obtidas em uma análise individual em cada etapa, considerando os percentuais de respostas em branco e não-compreendidas, bem como os percentuais de respostas classificadas como satisfatórias (S), parcialmente satisfatórias (PS) e insatisfatórias (I). A tabela também identifica a categoria na qual foi classificada cada resposta. Um exemplo auxiliará na interpretação da tabela: na linha 1, coluna ÑC, pode-se ver que o aluno 1 teve sua resposta à questão 9 , no pré-teste, classificada como não-compreendida, o que corresponde à categoria (d) na análise dessa questão (ver Tabela 1). Além disso, pode-se ver que o número de respostas não-compreendidas corresponde a $10 \%$ do total de respostas dadas por esse aluno. Ao lado, são mostrados os gráficos com o perfil de respostas dadas por cada estudante nas duas etapas, representado pelos percentuais de respostas classificadas como S, PS e I no pré- e no pós-teste. Cada categoria tem seu conteúdo sinteticamente apresentado na Tabela 1.

Esta análise individual, que foi feita a partir da leitura das respostas de cada aluno ao questionário como um todo, permitiu obter informações qualitativas mais detalhadas acerca das mudanças nas concepções sobre a natureza da ciência dos estudantes. Pode-se perceber, por exemplo, que, dos 31 estudantes que participaram da pesquisa, cerca de $87 \%$ aumentaram, na segunda etapa, o número de respostas que foram classificadas como $\mathbf{S}$, ao passo que cerca de $6 \%$ tiveram o número de respostas do tipo $\mathbf{S}$ diminuído. Houve ainda a ocorrência de aproximadamente $6 \%$ de estudantes que mantiveram, entre as duas etapas, o mesmo número de respostas com este tipo de classificação.

Já em relação às respostas que foram classificadas como I, percebeu-se que houve uma redução de mais de $87 \%$, comparando-se as duas etapas. Apenas um aluno teve o número de respostas insatisfatórias aumentado no pós-teste, o que corresponde a pouco mais de 3\% 
da amostra estudada. Por último, aproximadamente $9 \%$ dos alunos não tiveram aumento nem decréscimo do número de respostas do tipo $\mathbf{I}$.

Quanto às respostas classificadas como $\mathbf{P S}$, pode-se perceber uma distribuição mais equilibrada: cerca de $32 \%$ dos alunos mostraram um aumento do número de respostas deste tipo; $42 \%$, uma diminuição; e $26 \%$ mantiveram a mesma quantidade de respostas desse tipo.

A análise permitiu ainda identificar que por volta de $80 \%$ dos estudantes mostraram, simultaneamente, um aumento do número de respostas classificadas como $\mathbf{S}$ e uma redução do número de respostas classificadas como I. Apenas um aluno apresentou no pós-teste um menor número de respostas classificadas como $\mathbf{S}$ e um maior número de respostas classificadas com I, simultaneamente. Estes resultados tornam evidente a ocorrência de uma mudança positiva nas visões dos estudantes sobre a natureza da ciência, sob a influência de uma abordagem contextual do ensino da Mecânica Clássica, corroborando o que havíamos observado na análise geral.

Para ilustrar o grau de detalhamento a que se pode chegar com este tipo de análise qualitativa individual, apresentado de maneira sinóptica na Tabela 2, discutiremos a análise individual das respostas de dois alunos, escolhidos aleatoriamente.

O aluno 3 apresentou uma considerável mudança em suas concepções entre o pré- e o pós-teste. Houve um aumento das respostas classificadas como $\mathbf{S}$ (de $20 \%$ na $1^{\text {a }}$ etapa para $50 \%$ na $2^{a}$ ) e PS (de 20\% para 40\%), ao passo que houve uma redução significativa das respostas classificadas como I (de 50\% para 10\%). As respostas às questões nove e dez foram classificadas, em ambas as etapas, como $\mathbf{S}$. As respostas às questões dois e oito também se mantiveram, em ambas as etapas, nas mesmas categorias, sendo classificadas como PS. Entretanto, as respostas às questões três, seis e sete, que foram classificadas, no pré-teste, como I, foram aprimoradas pelos alunos no pós-teste, sendo classificadas como $\mathbf{S}$. Já as respostas às questões um, que não havia sido compreendida no pré-teste, e quatro, que havia sido classificada como I, passaram, ambas, a serem classificadas como PS, na segunda etapa.

Essas mudanças mostram, no caso desse aluno, um amadurecimento quanto: à compreensão do experimento como um método de investigação mediado por controle; ao entendimento dos conceitos de teorias e leis científicas; e ao reconhecimento da natureza conjectural das teorias científicas. Não houve mudança quanto à sua compreensão acerca da relação entre modelo e realidade, persistindo uma visão inadequada a este respeito.

O aluno 31, por sua vez, foi um dos que apresentou mudanças mais favoráveis nas concepções sobre a natureza da ciência. $\mathrm{Na} 1^{\text {a }}$ etapa, 20\% de suas respostas ao questionário foram classificadas como $\mathbf{S}$, ao passo que, na $2^{\text {a }}$ etapa, esse percentual aumentou para $70 \%$. As respostas classificadas como PS tiveram o percentual reduzido de $40 \%$ para $10 \%$, e as respostas classificadas como I, de 30\% para 10\%. Isso mostra uma evolução significativa na visão deste aluno quanto ao seu entendimento dos conceitos de ciência, experimento, teorias e leis científicas; do papel dos modelos científicos, da criatividade e imaginação, bem como dos fatores subjetivos e sociais na atividade científica. Somente na questão dois, o aluno mostrou uma mudança menos favorável, uma vez que sua resposta havia sido classificada como PS na $1^{\text {a }}$ etapa e passou a I na $2^{\text {a }}$ etapa. Por alguma razão que não conseguimos identificar, o aluno apresentou, no pós-teste, uma concepção menos adequada sobre o critério de demarcação entre a ciência e outras formas de conhecimento. 
A influência de uma abordagem contextual ...

Tabela 2. Legenda: $B$ = respostas em branco; $N C$ = respostas não compreendidas; $S=$ respostas classificadas como satisfatórias; PS = respostas classificadas como parcialmente satisfatórias; I - respostas classificadas como insatisfatórias; $\square 1^{\text {a }}$ etapa; $\square 2^{\text {a }}$ etapa.

\begin{tabular}{|c|c|c|c|c|c|c|c|c|c|c|c|}
\hline \multirow[b]{2}{*}{ Aluno } & \multicolumn{5}{|c|}{ Classificação $1^{a}$ etapa } & \multicolumn{5}{|c|}{ Classificação $2^{a}$ etapa } & \multirow[b]{3}{*}{ 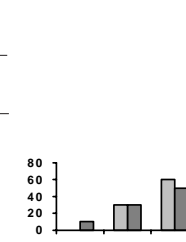 } \\
\hline & B & $\tilde{N} C$ & $\mathbf{s}$ & PS & $\mathbf{I}$ & B & $\tilde{N} C$ & $\mathbf{S}$ & PS & $\mathbf{I}$ & \\
\hline 1 & & $9 d$ & & $\begin{array}{c}1 \mathrm{a} ; 2 \mathrm{~b} \\
8 \mathrm{~b}\end{array}$ & $\begin{array}{l}3 a ; 4 a ; \\
5 b ; 6 a ; \\
7 a ; 10 b\end{array}$ & 5 & & $9 a$ & $\begin{array}{l}1 \mathrm{a} ; 2 \mathrm{~b} \\
8 \mathrm{~b}\end{array}$ & $\begin{array}{c}3 b ; 4 b ; \\
6 b ; 7 a ; \\
10 b\end{array}$ & \\
\hline & & $10 \%$ & & $30 \%$ & $60 \%$ & $10 \%$ & & $10 \%$ & $30 \%$ & $50 \%$ & $\mathrm{~S} \mathrm{PS}$ \\
\hline \multirow[t]{2}{*}{2} & & & $8 a ; 10 a$ & $\begin{array}{l}1 \mathrm{a} ; 2 \mathrm{a} \\
7 \mathrm{~b}\end{array}$ & $\begin{array}{c}3 a ; 4 a ; \\
5 b ; 6 a ; \\
9 b\end{array}$ & & $6 g$ & $\begin{array}{c}3 f ; 5 e \\
10 a\end{array}$ & $\begin{array}{c}1 \mathrm{a} ; 2 \mathrm{~b} \\
4 \mathrm{e} ; 7 \mathrm{~b} \\
\quad 8 \mathrm{~b}\end{array}$ & $9 b$ & \multirow{2}{*}{ 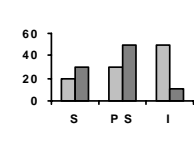 } \\
\hline & & & $20 \%$ & $30 \%$ & $50 \%$ & & $10 \%$ & $30 \%$ & $50 \%$ & $10 \%$ & \\
\hline \multirow[t]{2}{*}{3} & & $1 e$ & $9 a ; 10 a$ & $2 b ; 8 b$ & $\begin{array}{c}3 \mathrm{~b} ; 4 \mathrm{a} ; \\
5 \mathrm{a} ; 6 \mathrm{c} \\
7 \mathrm{a}\end{array}$ & & & $\begin{array}{l}\text { 3f; 6f; } \\
7 c ; 9 a \\
10 a\end{array}$ & $\begin{array}{l}1 a ; 2 b ; \\
4 e ; 8 b\end{array}$ & $5 a$ & \multirow{2}{*}{ 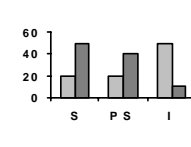 } \\
\hline & & $10 \%$ & $20 \%$ & $20 \%$ & $50 \%$ & & & $50 \%$ & $40 \%$ & $10 \%$ & \\
\hline \multirow[t]{2}{*}{4} & & & $\begin{array}{l}\text { 5c; 7c; } \\
9 a ; 10 a\end{array}$ & $\begin{array}{c}1 \mathrm{~b} ; 2 \mathrm{~b} \\
8 \mathrm{~b}\end{array}$ & $\begin{array}{c}3 b ; 4 a ; \\
6 d\end{array}$ & & & $\begin{array}{l}5 d ; 6 f ; \\
8 a ; 9 a ; \\
10 a\end{array}$ & $1 b ; 2 b$ & $\begin{array}{c}3 \mathrm{~b} ; 4 \mathrm{a} \\
7 \mathrm{a}\end{array}$ & \multirow{2}{*}{ 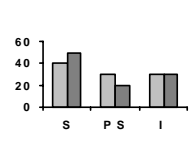 } \\
\hline & & & $40 \%$ & $30 \%$ & $30 \%$ & & & $50 \%$ & $20 \%$ & $30 \%$ & \\
\hline \multirow[t]{2}{*}{5} & & $9 d$ & & $\begin{array}{l}1 a ; 2 b \\
7 b ; 8 b\end{array}$ & $\begin{array}{c}3 a ; 4 a ; \\
5 a ; 6 e \\
10 b\end{array}$ & & $6 g$ & $\begin{array}{l}\text { 5e; } 9 a \\
10 c\end{array}$ & $\begin{array}{l}1 \mathrm{~b} ; 2 \mathrm{~b} ; \\
8 \mathrm{~b}\end{array}$ & $\begin{array}{l}\text { 3c; } 4 a \\
7 a\end{array}$ & \multirow{2}{*}{ 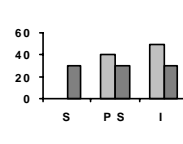 } \\
\hline & & $10 \%$ & & $40 \%$ & $50 \%$ & & $10 \%$ & $30 \%$ & $30 \%$ & $30 \%$ & \\
\hline \multirow[t]{2}{*}{6} & & & $7 c$ & $\begin{array}{c}1 \mathrm{a} ; 2 \mathrm{~b} \\
8 \mathrm{~b}\end{array}$ & $\begin{array}{l}3 a ; 4 b \\
5 a ; 6 c ; \\
9 b ; 10 b\end{array}$ & 2 & & $\begin{array}{l}4 c ; 7 c \\
8 a ; 9 a \\
10 c\end{array}$ & $1 \mathrm{a}$ & $\begin{array}{l}3 a ; 5 a ; \\
6 c\end{array}$ & \multirow{2}{*}{ 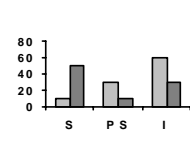 } \\
\hline & & & $10 \%$ & $30 \%$ & $60 \%$ & $10 \%$ & & $50 \%$ & $10 \%$ & $30 \%$ & \\
\hline \multirow[t]{2}{*}{7} & 5 & & $9 a ; 10 a$ & $\begin{array}{c}1 \mathrm{a} ; 2 \mathrm{~b} \\
8 \mathrm{~b}\end{array}$ & $\begin{array}{l}3 a ; 4 a ; \\
6 b ; 7 a\end{array}$ & 9 & & $\begin{array}{c}3 \mathrm{e} ; 7 \mathrm{c} \\
8 \mathrm{a} \\
10 \mathrm{a}\end{array}$ & $1 b ; 2 b$ & $\begin{array}{c}4 a ; 5 a \\
6 a\end{array}$ & $\left.\begin{array}{c}60 \\
40 \\
20 \\
0\end{array}\right] \square \square$ \\
\hline & $10 \%$ & & $20 \%$ & $30 \%$ & $40 \%$ & $10 \%$ & & $40 \%$ & $20 \%$ & $30 \%$ & Ps \\
\hline \multirow[t]{2}{*}{8} & & & $\begin{array}{c}8 a ; 9 a \\
10 a\end{array}$ & $\begin{array}{l}\text { 1b; 2a; } \\
\quad 7 \mathrm{~b}\end{array}$ & $\begin{array}{l}3 b ; 4 a ; \\
5 b ; 6 c\end{array}$ & & & $\begin{array}{l}\text { 5c; } 8 a \\
9 a ; 10 a\end{array}$ & $\begin{array}{l}1 \mathrm{~b} ; 2 \mathrm{~b} ; \\
\quad 7 \mathrm{~b}\end{array}$ & $\begin{array}{l}3 c ; 4 a ; \\
6 c\end{array}$ & $\left.\begin{array}{l}60 \\
40 \\
20\end{array}\right]-\square$ \\
\hline & & & $30 \%$ & $30 \%$ & $40 \%$ & & & $40 \%$ & $30 \%$ & $30 \%$ & Ps \\
\hline \multirow[t]{2}{*}{9} & & & 4c; 5d; & 1b; 2b; & 3c; 6b; & & & 3f; 4c; & $1 b ; 2 b$ & & \multirow{2}{*}{$\left.{ }_{0}^{100}{ }^{50}\right] \prod_{\text {s s }} \prod_{\text {l }}$} \\
\hline & & & $40 \%$ & $30 \%$ & $30 \%$ & & & $80 \%$ & $20 \%$ & & \\
\hline \multirow[t]{2}{*}{10} & & $\begin{array}{c}6 \mathrm{~g} ; 7 \mathrm{~d} \\
8 \mathrm{e}\end{array}$ & $\begin{array}{c}4 c ; 5 d \\
10 a\end{array}$ & $1 b ; 2 b$ & $3 c ; 9 c$ & & $\begin{array}{l}3 \mathrm{~g} ; 6 \mathrm{~g} \\
7 \mathrm{~d}\end{array}$ & $\begin{array}{l}4 c ; 5 c ; \\
8 a ; 9 a ; \\
10 c\end{array}$ & $1 b$ & $2 d$ & $\left.\begin{array}{l}60 \\
40 \\
20\end{array}\right]$ \\
\hline & & $30 \%$ & $30 \%$ & $20 \%$ & $20 \%$ & & $30 \%$ & $50 \%$ & $10 \%$ & $10 \%$ & 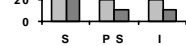 \\
\hline
\end{tabular}


Teixeira, E. S.; Freire Jr., O.; El-Hani, C. N.

Tabela 2. continuação

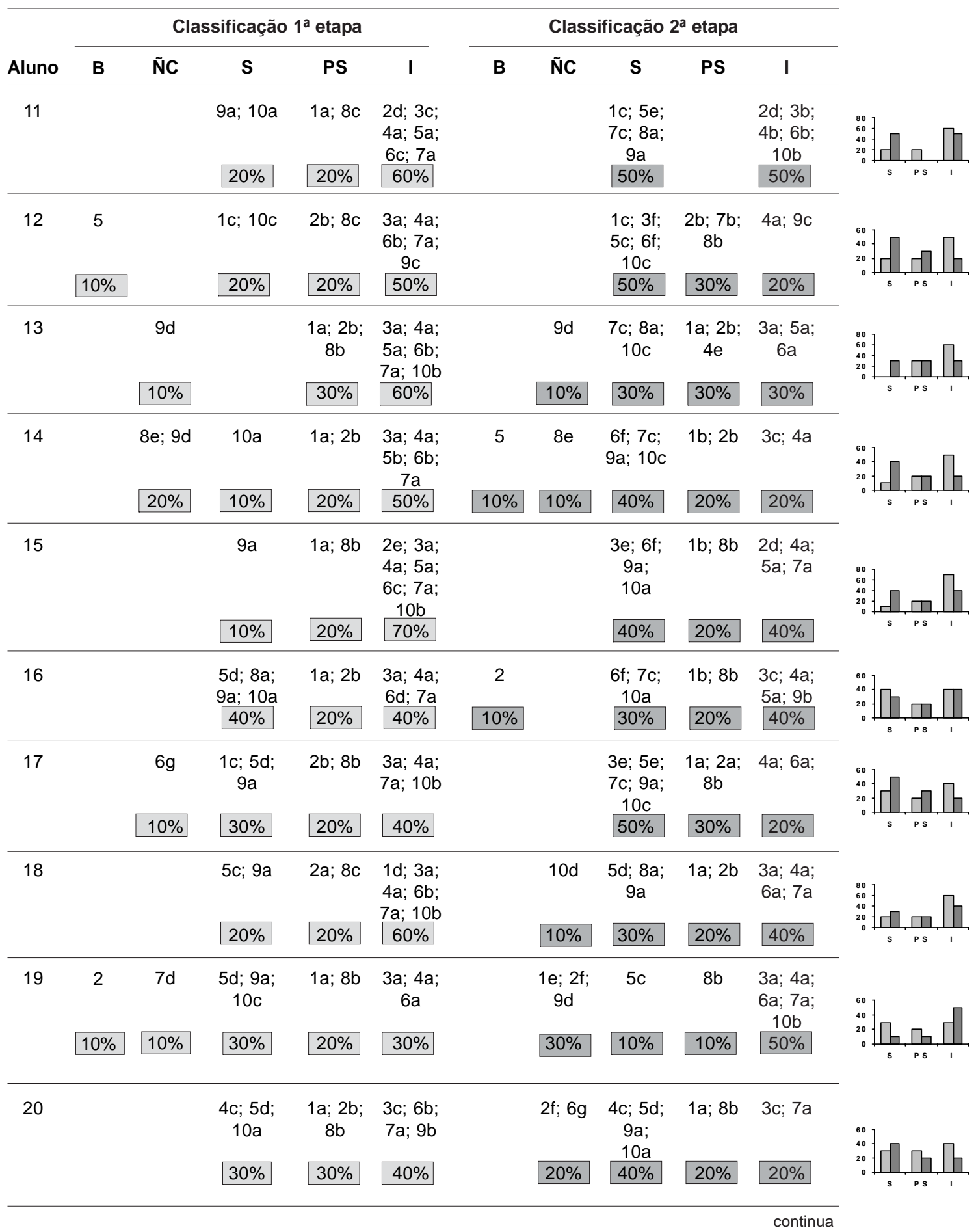


A influência de uma abordagem contextual ...

Tabela 2. continuação

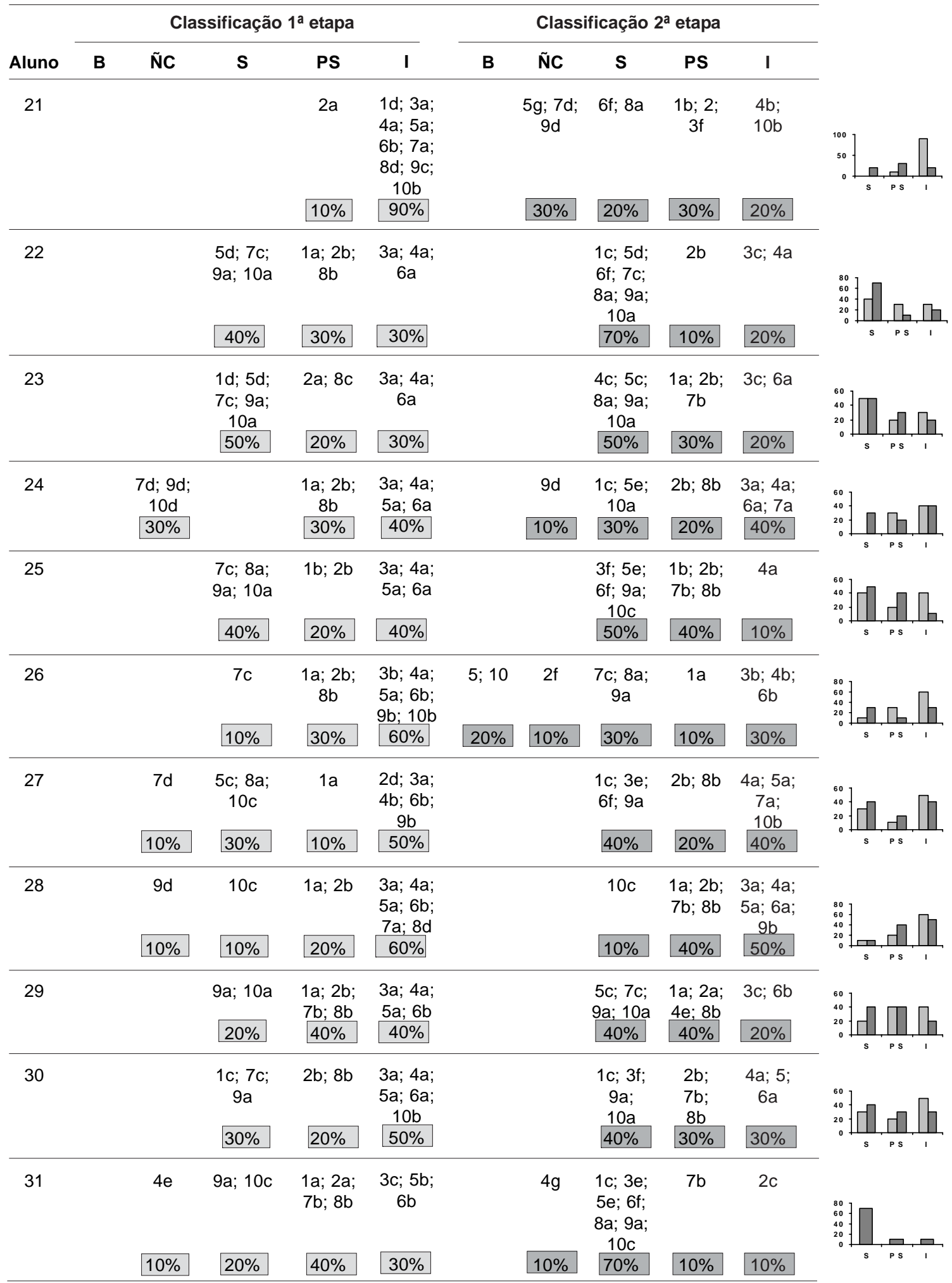




\section{Conclusão}

Esse trabalho se apoiou na ideia de que o ensino de física, no que diz respeito às concepções sobre a natureza da ciência que estejam de acordo com as tendências contemporâneas da epistemologia, pode tornar-se mais eficaz quando realizado por meio de uma abordagem contextualizada histórica e filosoficamente. Com o intuito de investigar isto em um estudo de caso, foi feita uma pesquisa de natureza qualitativa com estudantes de uma disciplina inicial do Curso de Física da UEFS, usando, como instrumentos, um questionário aberto (VNOS-C), aplicado em pré- e pós-teste, e entrevistas semiestruturadas com uma subamostra dos alunos. Os dados permitiram analisar as concepções prévias dos estudantes sobre alguns aspectos epistemológicos e as mudanças em tais concepções ao final da disciplina. Desse modo, foi possível examinar a influência que a abordagem contextual usada na disciplina teve sobre as visões dos alunos acerca da natureza da ciência.

Em conclusão, a despeito da existência de um foco de resistência à mudança, caracterizado pela presença, no pós-teste, de concepções empírico-indutivistas, parece ter havido, de um modo geral, um amadurecimento na compreensão dos estudantes que participaram da pesquisa acerca dos aspectos da natureza da ciência abordados, visto que apareceram, no final: maior diversificação nas visões sobre métodos científicos e sobre o papel do experimento na ciência; superação significativa da visão realista ingênua; maior entendimento acerca da natureza conjectural da ciência e da influência de fatores sociais na produção científica. A abordagem contextual usada no ensino sobre Mecânica Clássica parece ter influenciado tal amadurecimento.

A análise individual também se mostrou importante, por permitir uma análise mais aprofundada das mudanças que ocorreram com cada um dos alunos, no que diz respeito a cada concepção epistemológica avaliada pelo instrumento utilizado. Pôde-se perceber o aumento substancial das respostas classificadas como satisfatórias e redução equivalente das respostas classificadas como insatisfatórias.

Estas conclusões apontam a contribuição de uma abordagem contextual no contexto de uma disciplina de conteúdos específicos de um curso superior de física para a evolução das concepções sobre a natureza da ciência dos estudantes.

\section{Referências}

AAAS. American Association for the Advancement of Science. Benchmarks for Science Literacy: a project 2061 report. New York: Oxford University Press, 1993.

ABD-EL-KHALICK, F; BOUJAOUDE, S. An exploratory study of the knowledge base for science teaching. Journal of Research in Science Teaching, New York, v. 34, p. 673 699, 1997.

.; LEDERMAN, N. G. Improving science teachers' conceptions of nature of science: a critical review of the literature. International Journal of Science Education, London, v. 22, n. 7, p. 665-701, 2000a. 
A influência de uma abordagem contextual ...

; - The influence of history of science courses on students' views of nature of science. Journal of Research in Science Teaching, New York, v. 37, n. 10, p. 10571095, 2000b.

.; BELL, R. L.; LEDERMAN, N. The nature of science and instructional practice: making the unnatural natural. Science Education, New York, v. 82, n. 4, p. 417-437, 1998. ABELL, S. K.; SMITH, D. C. What is Science? Preservice elementary teacher's conceptions of the nature of science. International Journal of Science Education, London, v. 16, n. 4, p. 475-487, 1994.

ABRAMS, E.; WANDERSEE, J. H. How to infuse actual scientific research practices into science classroom instruction. International Journal of Science Education, London, v. 17, n. 6, p. 683-694, 1995.

AIKENHEAD, G. The measurement of High School students' knowledge about science and scientists. Science Education, New York, v. 57, n. 4, p. 539-549, 1973.

AKERSON, V. L.; ABD-EL-KHALICK, F.; LEDERMAN, N. G. Influence of a reflective explicit activity-based approach on elementary teachers' conceptions of nature of science. Journal of Research in Science Teaching, New York, v. 37, n. 4, p. 295-317, 2000.

ALTERS, B. J. Whose nature of science? Journal of Research in Science Teaching, New York, v. 34, n. 1, p. 39-55, 1997.

BELL, R. et al. The nature of science and science education: a bibliography. Science $\boldsymbol{\&}$ Education, Dordrecht, v. 10, n. 1-2, p. 187-204, 2001.

BRICKHOUSE, N. W. The teaching of the philosophy of science in secondary classrooms: case studies of teachers' personal theories. International Journal of Science Education, London, v. 11, n. 4, p. 437-449, 1989.

Teachers' beliefs about the nature of science and their relationship to classroom

practice. Journal of Teacher Education, Washington, v. 41, n. 3, p. 53-62, 1990.

; BODNER, G. M. The beginning science teacher: classroom narratives of

convictions and constraints. Journal of Research in Science Teaching, New York, v. 29, n. 5, p. 471-485, 1992.

BRUSH, S. Thomas Kuhn as a historian of science. Science $\boldsymbol{\&}$ Education, Dordrecht, v. 9 , n. 1-2, p. 39-58, 2000.

BURBULES, N. C.; LINN, M. C. Science education and philosophy of science: congruence or contradiction? International Journal of Science Education, London, v. 13, n. 3, p. 227-241, 1991.

CARVALHO, A. M. P.; VANNUCCHI, A. I. O currículo de Física: inovações e tendências nos anos noventa. Investigações em Ensino de Ciências, Porto Alegre, v. 1, n. 1, p. 3-19, 1996. 
Teixeira, E. S.; Freire Jr., O.; El-Hani, C. N.

.; . History, philosophy and science teaching: some answers to "how?".

Science \& Education, Dordrectht, v. 9, n. 5, p. 427-448, 2000.

CLEMINSON, A. Establishing an epistemological base for science teaching in the light of contemporary notions of the nature of science and of how children learn science. Journal of Research in Science Teaching, New York, v. 27, n. 5, p. 429-445, 1990.

CUDMANI, L. C.; SANDOVAL, J. S. Cambios en las concepciones de los estudiantes sobre la ciencia: resultados de una experiencia de aula. Revista Brasileira de Ensino de Física, São Paulo, v. 22, n. 1, p. 106-113, 2000.

DRAKE, S. Galileu. 3. ed. Lisboa: Publicações Dom Quixote, 1980.

DRIVER, R. et al. Young peoples' images of science. Buckingham: Open University Press, 1996.

DUSCHL, R. Science education and philosophy of science: twenty-five years of mutually exclusive development. School Science and Mathematics, Menasha, v. 85, n. 7, p. 541-555, 1985.

EL-HANI, C. N.; TAVARES, E. J. M.; ROCHA, P. L. B. Concepções epistemológicas de estudantes de Biologia e sua transformação por uma proposta explícita de ensino sobre história e filosofia das ciências. Investigações em Ensino de Ciências, Porto Alegre, v. 9 , n. 3, p. 265-313, 2004.

FREIRE JR., O. A relevância da filosofia e da história das ciências para a formação dos professores de ciências. In: SILVA FILHO, W. J. (Ed.). Epistemologia e ensino de ciências. Salvador: Arcádia/UCSal, 2002. p. 13-30.

; TENÓRIO, R. M. A graduate programme in history, philosophy and science teaching in Brazil. Science \& Education, Dordrecht, v. 10, n. 6, p. 601-608, 2001.

GALLAGHER, J. J. Prospective and practicing secondary school science teachers' knowledge and beliefs about the philosophy of science. Science Education, New York, v. 75, n. 1, p. 121-133, 1991.

GATTI, S. R. T. Análise de uma ação didática centrada na utilização da história da ciência: uma contribuição para a formação inicial do docente de Física. 2005. 312f. Tese (Doutorado em Educação) - Faculdade de Educação, Universidade Estadual de Campinas, Campinas, 2005.

GIL-PÉREZ, D. et al. Para uma imagem não-deformada do trabalho científico. Ciência \& Educação, Bauru, v. 7, n. 2, p. 125-153, 2001.

HANSEN, T. B. (Ed.). Introduction. In: . (Ed.). The role of philosophy of science and ethics in University Science Education. Göteborg: NSU Press, 2002. p. $17-22$.

HARRES, J. B. S. Uma revisão de pesquisas nas concepções de professores sobre a natureza da ciência e suas implicações para o ensino. Investigações em Ensino de Ciências, Porto Alegre, v. 4, n. 3, p. 197-211, 1999. 
A influência de uma abordagem contextual ...

HODSON, D. Philosophy of science and science education. In: MATTHEWS, M. R. (Org.). History, philosophy and science teaching: selected readings. Toronto: OISE Press, 1991. p. 19-32.

KING, B. B. Beginning teachers' knowledge of and attitude towards history and philosophy of science. Science Education, v. 75, n. 1, p. 135-141, 1991.

KOYRÉ, A. Estudos de história do pensamento científico. Rio de Janeiro: Forense Universitária, 1982.

LAKIN, S.; WELLINGTON, J. Who will teach the "Nature of Science"? Teachers' view of science and their implications for science education. International Journal of Science Education, London, v. 16, n. 2, p. 175-190, 1994.

LAUDAN, R. In: HEILBRON, J. L. (Ed.). The Oxford Companion to the History of Modern Science. New York: Oxford University Press, 2003. p. 670-671.

LEACH, J. et al. Epistemological understanding in science learning: the consistency of representations across contexts. Learning and Instruction, Oxford, v. 10, n. 6, p. 497-527, 2000.

LEDERMAN, N. G. Students' and teachers' conceptions of the nature of science: a review of the research. Journal of Research in Science Teaching, New York, v. 29, n. 4, p. 331-359, 1992.

Teachers' understanding of the nature of science and classroom practice: factors that facilitate or impede the relationship. Journal of Research in Science Teaching, New York, v. 36, n. 8, p. 916-929, 1999.

.; O’MALLEY, M. Student's perceptions of tentativeness in science: development, use and sources of change. Science Education, New York, v. 74, n. 2, p. 225-239, 1990.

.; ZEIDLER, D. L. Science teacher's conceptions of the nature of science: do they really influence teaching behavior? Science Education, New York, v. 7, n. 5, p. 721734, 1987.

.; WADE, P. D.; BELL, R. L. Assessing the nature of science: what is the nature of our assessments? Science and Education, Dordrecht, v. 7, n. 6, p. 595-615, 1998.

. et al. Pre-service teachers' understanding and teaching of the nature of science: an intervention study. Canadian Journal of Science, Mathematics, and Technology Education, Toronto, v. 1, n.2, p. 135-160, 2001.

. Views of nature of science questionnaire (VNOS): toward valid and meaningful assessment of learners' conceptions of nature of science. Journal of Research in Science Teaching, New York, v. 39, n. 6, p. 497-521, 2002.

LEITE, L. History of science in science education: development and validation of a checklist for analysing the historical content of science textbooks. Science \& Education, Dordrecht, v. 11, n.4, p. 333-359, 2002. 
Teixeira, E. S.; Freire Jr., O.; El-Hani, C. N.

LEWIS, J. L. O ensino da física escolar. Lisboa: Editorial Estampa Ltda, 1976. v. 1.

LÜDKE, M.; ANDRÉ, M. E. D. A. Pesquisa em educação: abordagens qualitativas. São Paulo: EPU, 1986.

MACH, E. Desarollo histórico-critico de la mecanica. Buenos Aires: Espasa Calpe Argentina, 1949.

MARTIN, B.; KASS, H.; BROUWER, W. Authentic science: a diversity of meanings.

Science Education, New York, v. 74, n. 5, p. 541-554, 1990.

MASSONI, N. T. Estudo de caso etnográfico sobre a contribuição de diferentes visões epistemológicas contemporâneas na formação de professores de física. 2005. 275f. Dissertação (Mestrado) - Instituto de Física, Universidade Federal do Rio Grande do Sul, Porto Alegre, 2005.

MATTHEWS, M. R. History, philosophy and science teaching: the present reapprochement. Science \& Education, Dordrecht, v. 1, n. 1, p. 11-48, 1992.

Science teaching: the role of history and philosophy of science. New York: Routledge, 1994.

In defense of modest goals when teaching about the nature of science. Journal of Research in Science Teaching, New York, v. 35, n. 2, p. 161-174, 1998.

. Time for science cducation: how teaching the history and philosophy of pendulum motion can contribute to science literacy. New York: Plenum Press, 2000.

MCCOMAS, W. F. The nature of science in science education: rationales and strategies. Dordrecht: Kluwer, 1998.

.; ALMAZROA, H.; CLOUGH, M. P. The nature of science in science education: an introduction. Science \& Education, Dordrecht, v. 7, n. 6, p. 511-532, 1998.

MCEVOY, J. G. Modernism, postmodernism and the historiography of science. Historical Studies in the Physical and Biological Sciences, Berkeley, v. 37, n. 2, p. 383-408, 2007.

MELLADO, V. Preservice teacher's classroom practice and their conception of the nature of science. Science \& Education, Dordrecht, v. 6, n. 4, p. 331-354, 1997.

MONK, M.; OSBORNE, J. Placing the history and philosophy of science on the curriculum: a model for the development of pedagogy. Science Education, New York, v. 81, n. 4, p. 405-424, 1997.

MOSS, D. M.; ABRAMS, E. D.; ROBB, J. Examining student conceptions of the nature of science. International Journal of Science Education, London, v. 23, n. 8, p. 771-790, 2001.

NCC. NATIONAL CURRICULUM COUNCIL. Science in the national curriculum. York: NCC, 1988. 
A influência de uma abordagem contextual ...

NRC. NATIONAL RESEARCH COUNCIL. National science education standards. Washington, DC: National Academic Press, 1996.

NUSSBAUM, J. Classroom conceptual change: philosophical perspectives. International Journal of Science Education, London, v. 11, n. esp., p. 530-540, 1989.

POMEROY, D. Implications of teachers' beliefs about the nature of science: comparison of the beliefs of scientists, secondary science teachers, and elementary teachers. Science Education, New York, v. 77, n. 3, p. 261-278, 1993.

PORLÁN, R. Las concepciones epistemológicas de los professores: el caso de los estudiantes de magisterio. Investigación en la Escuela, Sevilla, v. 22, p. 67-84, 1994. .; RIVERO, A.; MARTÍN DEL POZO, R. Conocimiento profesional y epistemologia de los professores - I: teoria, metodos y instrumentos. Enseñanza de las Ciencias, Barcelona, v. 15, n. 2, p. 155-173, 1997.

ROBINSON, J. T. Science teaching and the nature of science. Journal of Research in Science Teaching, New York, v. 3, n. 1, p. 37-50, 1965.

ROSA, L. P. Tecnociências e humanidades: novos paradigmas, velhas questões. São Paulo: Paz e Terra, 2006.

ROTH, W. M.; LUCAS, K. B. From "truth" to "invented reality": a discourse analysis of high school physics students' talk about scientific knowledge. Journal of Research in Science Teaching, New York, v. 34, n. 2, p. 145-179, 1997.

ROTH, W. M.; ROYCHONDHURY, A. Students' epistemologies and views about knowing and learning. Journal of Research in Science Teaching, New York, v. 31, n. 1, p. 5-30, 1994.

RUTHERFORD, F. J. Fostering the history of science in american science education. Science \& Education, Dordrecht, v. 10, n. 6, p. 569-580, 2001. .; AHLGREN, A. Ciência para todos. Lisboa: Gradiva, 1995.

RYAN, A. G.; AIKENHEAD, G. S. Students' preconceptions about the epistemology of science. Science Education, New York, v. 76, n. 6, p. 559-580, 1992.

SEPÚLVEDA, C. Limites e perspectivas da formação continuada dos professores de ciências: experiência no Programa Pró-Ciências CAPES/UEFS. Revista da FAEEBA, Salvador, v. 14, p. 159-176, 2001.

SEROGLOU, F.; KOUMARAS, P. The contribution of the history of physics in physics education: a review. Science \& Education, Dordrecht, v. 10, n. 1-2, p. 153-172, 2001.

SETTLE, T. B. Galileo's use of experiment as a tool of investigation. In: MCMULLIN, E. (Ed.). Galileo - man of science. New Jersey: The Scholar's Bookshelf, 1967. p. 315-337.

SOLOMON, J. et al. Teaching about the nature of science through history: action research in the classroom. Journal of Research in Science Teaching, New York, v. 29, n. 4, p. 409-421, 1992. 
Teixeira, E. S.; Freire Jr., O.; El-Hani, C. N.

SOLOMON, J.; DUVEEN, J.; SCOT'T, L. Pupils' images of scientific epistemology.

International Journal of Science Education, London, v. 16, n. 3, p. 361-373, 1994.

TEIXEIRA, E. S. A influência de uma abordagem contextual nas concepções sobre a natureza da ciência: um estudo de caso com estudantes de física da UEFS. 2003. 130f. Dissertação (Mestrado) - Programa de Pós-graduação em Ensino, Filosofia e História das Ciências, Universidade Federal da bahia, Universidade Federal de Feira de Santana, Salvador, Bahia, 2003.

.; EL-HANI, C. N.; FREIRE, O. Concepções de estudantes de física sobre a natureza da ciência e sua transformação por uma abordagem contextual do ensino de ciências. Revista Brasileira de Pesquisa em Educação em Ciências, Belo Horizonte, v. 1, n. 3, p. 111-123, 2001.

TRENT, J. The attainment of the concept "understanding science" using contrasting physics courses. Journal of Research in Science Teaching, New York, v. 3, n. 3, p. 224229, 1965.

WANG, H.; SCHMIDT, W. History, philosophy and sociology of science in science education: results from the third international mathematics and science study. Science $\boldsymbol{\&}$ Education, Netherlands, v. 10, n. 1-2, p. 51-70, 2001.

WITTGENSTEIN, L. On certainty. Oxford: Blackwell, 1969.

ZIMAN, J. Getting scientists to think about what they are doing. In: HANSEN, T. (Ed.). The role of philosophy of science and ethics in university science education. Göteborg: NSU Press, 2002. p. 23-44.

Artigo recebido em dezembro de 2008 e aceito em outubro de 2009. 
A influência de uma abordagem contextual ...

\section{ANEXO 1}

Questionário VNOS(C)

Nome:

Data: $\quad 1 \quad 1 \quad$

Instruções

- Por favor, responda cada uma das seguintes questões. Inclua exemplos relevantes sempre que possível. Você pode usar o verso de uma página se necessitar de mais espaço.

- Não há respostas "certas" ou "erradas" para as seguintes questões. Nós estamos interessados apenas em sua opinião sobre um conjunto de questões acerca da ciência.

1. Na sua visão, o que é ciência? O que torna a ciência (ou uma disciplina científica como a Física, a Biologia etc.) diferente de outras formas de investigação (por exemplo, religião, filosofia)?

2. O que é um experimento?

3. O desenvolvimento do conhecimento científico requer experimentos?

- Se sim, explique por quê. Dê um exemplo para defender sua posição.

. Se não, explique por quê. Dê um exemplo para defender sua posição.

4. Livros-texto de ciência frequentemente representam o átomo como um núcleo central composto de prótons (partículas carregadas positivamente) e nêutrons (partículas neutras), com elétrons (partículas carregadas negativamente) orbitando ao redor daquele núcleo. Qual o grau de certeza que os cientistas têm acerca da estrutura do átomo? Que evidência específica, ou tipos de evidência, você pensa que os cientistas utilizaram para determinar com que um átomo se parece?

5. Há uma diferença entre uma teoria científica e uma lei científica? Ilustre sua resposta com um exemplo.

6. Após os cientistas terem desenvolvido uma teoria científica (por exemplo, a teoria atômica, a teoria da evolução), a teoria pode transformar-se?

. Se você acredita que as teorias científicas não mudam, explique por quê. Defenda sua resposta com exemplos.

. Se você acredita que as teorias científicas de fato mudam:

(a) Explique por que as teorias mudam.

(b) Explique por que nós nos preocupamos em aprender teorias científicas. Defenda sua resposta com exemplos.

7. Livros-texto de ciências definem uma espécie como um grupo de organismos que compartilham características similares e podem cruzar uns com os outros produzindo filhos férteis. Qual o grau de certeza que os cientistas têm acerca de sua caracterização do que é uma espécie? Que evidência específica você pensa que os cientistas utilizaram para determinar o que é uma espécie?

555

Ciência đ̊̃ Educação, v. 15, n. 3, p. 529-556, 2009 
Teixeira, E. S.; Freire Jr., O.; El-Hani, C. N.

8. Os cientistas realizam experimentos/investigações científicas quando estão tentando encontrar respostas para as questões que eles propuseram. Os cientistas usam sua criatividade e imaginação durante suas investigações?

. Se sim, então em que estágios das investigações você acredita que os cientistas utilizam sua imaginação e criatividade: projeto e planejamento; coleta de dados; após a coleta de dados? Por favor, explique por que os cientistas usam a imaginação e a criatividade. Forneça exemplos se for apropriado. . Se você acredita que cientistas não usam a imaginação e a criatividade, por favor explique por quê. Forneça exemplos se for apropriado.

9. Acredita-se que há cerca de 65 milhões de anos os dinossauros se extinguiram. Entre as hipóteses formuladas pelos cientistas para explicar a extinção, duas gozam de maior apoio. A primeira, formulada por um grupo de cientistas, sugere que um imenso meteorito atingiu a Terra há 65 milhões de anos e acarretou uma série de eventos que causou a extinção. A segunda hipótese, formulada por um outro grupo de cientistas, sugere que grandes e violentas erupções vulcânicas foram responsáveis pela extinção. Como essas conclusões diferentes são possíveis se os cientistas de ambos os grupos tiveram acesso a e utilizaram o mesmo conjunto de dados para obter suas conclusões?

10. Algumas pessoas afirmam que a ciência é impregnada por valores sociais e culturais. Isto é, a ciência reflete os valores sociais e políticos, as suposições filosóficas e as normas intelectuais da cultura na qual ela é praticada. Outras pessoas afirmam que a ciência é universal. Isto é, a ciência transcende as fronteiras nacionais e culturais e não é afetada por valores sociais, políticos e filosóficos e pelas normas intelectuais da cultura na qual ela é praticada.

Se você acredita que a ciência reflete valores sociais e culturais, explique por que e como. Defenda sua resposta com exemplos.

. Se você acredita que a ciência é universal, explique por que e como. Defenda sua resposta com exemplos. 